Please do not remove this page

RMIT

UNIVERSITY

\title{
Ventilation control for improved cabin air quality and vehicle safety
}

Galatsis, Kosmas; Wlodarski, W; Li, Yongxiang; Kalantar-Zahed, Koroush

https://researchrepository.rmit.edu.au/esploro/outputs/9921857976501341/filesAndLinks?institution=61RMIT_INST\&index=null

Galatsis, K., Wlodarski, W., Li, Y., \& Kalantar-Zahed, K. (2001). Ventilation control for improved cabin air quality and vehicle safety. Proceedings of the 53rd IEEE Vehicular Technology Conference, Spring 2001, 3018-3021. https://doi.org/10.1109/VETECS.2001.944157

Published Version: https://doi.org/10.1109/VETECS.2001.944157

Repository homepage: https://researchrepository.rmit.edu.au

(c) 2001 IEEE. Personal use of this material is permitted. However, permission to reprint/republish this material for advertising or promotional purposes or for creating new collective works for resale or redistribution to servers or lists, or to reuse any copyrighted component of this work in other works must be obtained from the IEEE.

Downloaded On 2023/04/26 22:35:52 +1000 


\title{
Ventilation Control for Improved Cabin Air Quality and Vehicle Safety
}

\author{
Kosmas Galatsis, Wojtek Wlodarski, Yongxiang Li, Kourosh Kalantar-zadeh \\ Sensor Technology Laboratory, School of Electrical and Computer Systems \\ Engineering, Royal Melbourne Institute of Technology, \\ GPO Box 2476V, Melbourne, Australia \\ email: koz@ieee.org
}

\begin{abstract}
Motor vehicles are a prime pollution source. In certain circumstances, the vehicles exhaust may enter the vehicle cabin causing driver discomfort and adverse health effects. As a result, driver reflexes decrease and fatigue may be inhibited. Furthermore, the oxygen depletion due to vehicle occupant breathing can also result threaten vehicle safety. Cabin air filters and ventilation control are capable of improving passenger comfort, however an intelligent gas sensing system is required to trigger effective action to be taken to prevent driver fatigue and exhaust gas suicides. An action plan is provided based on a gas sensing system integrated to the engine and body management systems of a vehicle.
\end{abstract}

\section{Introduction}

Motor vehicles are a prime pollution source, accounting for about $30 \%$ emissions of nitrogen oxides, $50 \%$ of hydrocarbons, $60 \%$ of lead and $60 \%$ of carbon monoxide in cities of developed countries [1]. Outdoor pollution levels are a key environmental concern, however, air quality within automobiles and other confined spaces such as planes has only recently gained much public interest as a health concern [2-5].

A vehicle cabin is an enclosed environment, typically less than $5 \mathrm{~m}^{3}$ in volume. With such a small volume, occupant discomfort can quickly be caused by suspended particulate, dusts, fumes, and smokes entering the cabin via the ventilation system, window entrance and poor door seals. Cabin air filters with active carbon are used to reduce unwanted smetls and particulate [6] entering the cabin through the Heating Ventilation and Air Conditioning System (HVAC). Although cabin air filters eliminates unwanted particulate, a viable solution to prevent unwanted and noxious gases within the vehicle from entering and building-up is difficult to control. Two primary health concerns arise from poor cabin air quality $[2,3]$. First, tragic exhaust gas suicides caused by $\mathrm{CO}$ poisoning and second, death and injuries from fatalities resulting from driver fatigue possibly caused by the presence of poor cabin air quality. This paper identifies problems resulting from poor cabin air quality and schemes which could be employed to prevent adverse health effects by employing gas sensors for ventilation, window and engine management control.

\section{Vehicle Safety Concerns}

\subsection{Motor Vehicle Exhaust Gas Suicides}

Motor Vehicle Exhaust Gas Suicides (MVEGS) are caused by carbon monoxide poisonings. In Australia there were 509 motor vehicle exhaust gas suicides in 1995 , representing $22 \%$ of total suicides [ 7 ]. Comparing, in the US in 1996 there were 1508 suicides and 219 accidental deaths caused by $\mathrm{CO}$ poisoning from motor vehicle exhaust gas, furthermore, there was an average suicide rate of 1,686 per year average from 1992-1996 [8]. Many deaths are also attributed to fatal unintentional carbon monoxide poisoning in and around motor vehicles, 57\% of unintentional $\mathrm{CO}$ poisoning deaths occurred in automobiles [9].

The Environmental Protection Agency (USA) and the World Health Organisation [10] employ $9 \mathrm{ppm}$ as the CO threshold limit for outside air time weighted average (TWA) over an eight hour period. The National Occupational Health and Safety Commission of Australia mandate $30 \mathrm{ppm}$ (TWA -8 hours) as the CO exposure limit [11]. The National Institute for Occupational Safety and Health (NIOSH, USA) and the Occupational Safety and Health Administration (OSHA, USA) use $35-50 \mathrm{ppm}$ CO (TWA - 8 hours) as the limit for industrial exposure. Exposure of $400 \mathrm{ppm} \mathrm{CO}$ for 1-2 hours results in serious headache, fatigue, nausea and dizziness.

Many leading researchers are battling to fight MVEGS caused by $\mathrm{CO}$ poisonings however as of yet no viable complete solution has been presented [12-14]. Partial solutions such as the modification of exhaust pipes so that a hose cannot be inserted have been introduced on some vehicles. Other improvements are to engine design and catalytic conversion techniques to complete the 
combustion process and thereby virtually eliminate $\mathrm{CO}$ emissions, however, catalytic converters required time to reach their optimum operating temperature. The most promising method to prevent MVEGS is with a vehicle cabin air quality monitor $[2,3,5]$. The mandatory incorporation into new vehicles of a multi-gas sensing device which monitors cabin air quality could trigger a visual or audible warning, and in the worst case may shut down the engine, hence completely preventing $\mathrm{CO}$ poisoning. An Australian parliamentary enquiry committee on "transport fatigue" has also encouraged this path to preventing MVEGS [5]. Studies have shown [3] that $\mathrm{CO}$ rapidly increases whilst $\mathrm{O}_{2}$ levels rapidly decrease as shown in Fig.1. Such gas behavior of $\mathrm{CO}$ and $\mathrm{O}_{2}$ could be used as a gas signature to detect a suicide attempt [3].

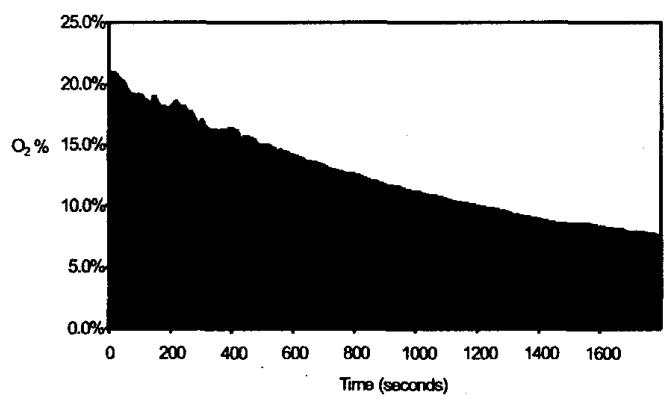

Figure 1: $\mathrm{O}_{2}$ depletion in a vehicle cabin during a suicide attempt [3].

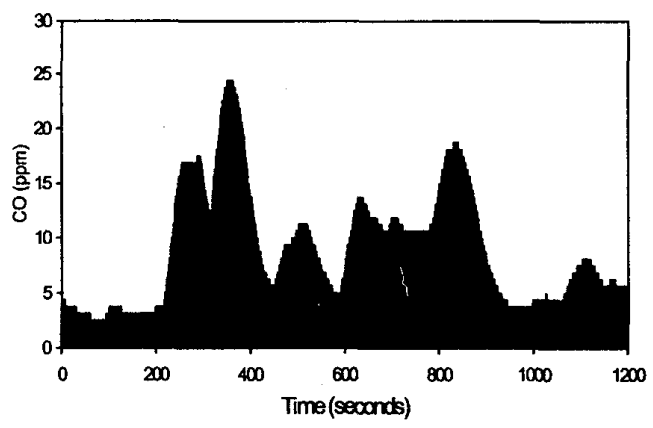

Figure 2: CO profile whilst driving in heavy city traffic with both front windows lowered [3].

However, false alarms are a common problem in commercially available home $\mathrm{CO}$ detectors. Similar problems could also be experienced in a cabin environment since conditions are dynamic and the environment considered as harsh. Fig. 3 shows the dynamic behaviour of $\mathrm{CO}$ within a vehicle over a 20 minute period [3]. Cabin CO levels fluctuate, reaching up to $25 \mathrm{ppm}$ in heavy traffic, others have recorder up to 70 ppm [13]. Such turbulent CO swings should not cause "flase alarms" to be triggered when detecting for a suicide attempt.

\subsection{Driver Fatigue}

Driver fatigue is a primary concern in the battle to decrease road fatalities. In Australia research indicates that fatigue is the principal cause for $20 \%$ of crashes involving a fatality [16]. Fatigue often is associated with feelings of drowsiness or sleepiness, loss of alertness, inability to concentrate and slowed reactions. Fatiguerelated crashes typically are more severe than other road crashes because they involve complete loss of control by the driver. Aside from lack of sleep, fatigue symptoms could be instigated by exhaust pollutants such as $\mathrm{CO}$, $\mathrm{NO}_{x}$, and hydrocarbons causing headaches, nausea and dizziness and inducing poor hand-eye coordination which may increase the likelihood of a collision $[17,18]$.

Not only are exhaust emissions a health hazard but so too is our natural breathing process in a confined environment. In the course of breathing, we exhale carbon dioxide which in an indoor environment such as a vehicle cabin, can displace oxygen, leaving the environment oxygen deficient. Adverse human health effects may manifest due to the high carbon dioxide and low oxygen concentrations, the situation being exaggerated when vehicle occupants choose to operate the HVAC system in the "recycle" mode aiming to prevent outdoor-polluted air from entering. A study on fatal single vehicle crashes highlights it is more likely to have windows closed, the heater on, and less likely to have fresh air and air conditioning fitted [19]. The Occupational Safety and Health Administration (OSHA), U.S. Department of Labor has issued its final rules on Confined Spaces (29 CFR 1910.146). It states a "hazardous atmosphere" is one which has an atmospheric oxygen concentration below $19.5 \%$ [20]. Concentration levels of $\mathrm{O}_{2}$ deplete below $19.5 \%$. As shown from Fig. 3, $19.1 \%$ of $\mathrm{O}_{2}$ has been detected within a 15 minute period with 2 vehicle occupants in a sedan.

Gas sensors are installed in some HVAC systems to automatically switch the ventilation system in recycle mode when poor ambient air is entering the vehicle, aiming to improve "driver comfort". However, poor cabin air quality induced by occupant breathing has been overlooked by current HVAC systems which could potentially lead to collisions. Continuous air sampling both in and out (ambient) of the car cabin is required to achieve a successful air quality analysis, and only then can the system determine the optimal HVAC settings. 


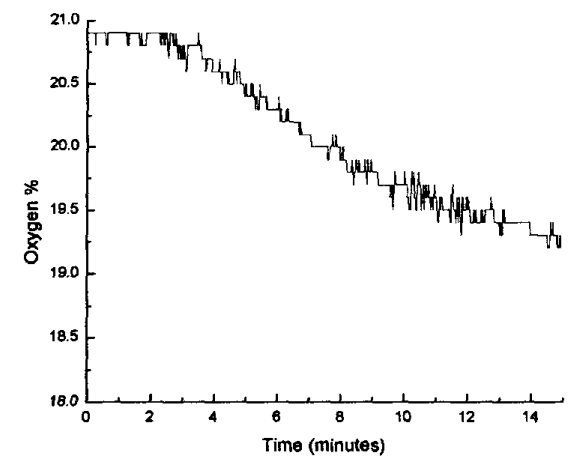

Figure 3: Vehicle cabin oxygen profile whilst city driving with the HVAC set on the "recycle" air mode [2].

Image detection system monitoring eye, eye-lid and steering wheel movements can to detect drowsiness and driver attentiveness have shown to be successful [21]. Other systems use complex mathematical algorithms to visually analyse the road, referencing the road curb to determine if the vehicle is drifting. However, by directly analysing cabin air quality with gas sensing, the driver can be warned to prevent effects of fatigue and drowsiness from occurring.

\section{Ventilation control and Action Plan}

The absolute concentration of particular gas specie $\left(C_{x}\right)$ in the vehicle cabin is dependant on the exhaust flow rate $(F)$, time $(T)$, cabin volume $(V)$, and cabin seal $(S)$. Therefore,

$$
C_{x}=f(F, T, V, S)
$$

Concentrations of carbon monoxide $\left(C_{C O}\right)$, and oxygen $\left(\mathrm{C}_{\mathrm{O} 2}\right)$ have been identified as important gas species contributing to poor air quality $[2,3,4,5]$. The summation of each absolute gas specie concentration could give rise to an air quality factor $\left(A Q_{c a b i n}\right)$ such as:

$$
A Q_{c a b i n}=\alpha C_{C O}+\delta\left(C_{O 2}\right)^{-I}
$$

Where $\alpha$, and $\delta$ are proportionality coefficients. It should be noted that others gas species such as hydrocarbons and nitrogen oxides should not be ignored. Absolute threshold limits could then be set for MVEGS ( $\left.A Q_{\text {suicide }}\right)$ and driver fatigue $\left(A Q_{\text {fatigue }}\right)$. For increased reliability and effective suicide attempt identification, the change of air quality with time ( $\left.d A Q_{c a b i n} / d t\right)$ should also be incorporated into the driver fatigue and suicide detecting algorithms:

$$
\frac{d A Q_{\text {cabin }}}{d t}=\alpha \frac{\partial C_{C O}}{\partial t}+\delta \frac{\partial\left(C_{O 2}\right)^{-1}}{\partial t}
$$

An alarm threshold, $d A Q_{\text {suicide }} / d t$, should be set correspondingly. Therefore, the cabin gas-sensing system should include both absolute and changing air quality factors, to determine if an action is to be taken.

\subsection{Suicide Attempt Action Plan}

A suicide attempt could be identified if $A Q_{\text {cabin }}>$ $A Q_{\text {suicides }}$ and $d A Q_{\text {cabin }} / d t>\Delta A Q_{\text {suicide }} / d t$. The following action could be taken:

1. Determine if the vehicle is in motion, if so,

2. Shut Down Engine,

3. Lower Windows,

4. HVAC on fresh air mode (if, $A Q_{\text {ambient }}<A Q_{c a b i n}$ ),

5. Disable ignition for $t_{x}$

\subsection{Driver Fatigue Action Plan}

If poor cabin air quality is detected, $A Q_{\text {cabin }}>A Q_{\text {fatigue }}$ within the vehicle cabin the following measures may be taken:

1. Analyse ambient air quality $\left(A Q_{\text {ambien }}\right)$,

2. Switch ventilation to fresh air mode if $A Q_{\text {cabin }}<A Q_{\text {ambient, }}$

3. Switch ventilation to recycle mode if $A Q_{c a b i n}>$ $A Q_{\text {ambient, }}$

4. $A Q_{\text {cabin }}>A Q_{\text {fatigue }}$ for time $t_{A Q I}$ then visually alert driver,

5. $A Q_{\text {cabin }}>A Q_{\text {fatigue }} t_{A Q 2}$ then audibly alert driver where $t_{A Q 2}>t_{A Q I}$.

$d A Q_{\text {cabin }} / d t$ could also be included in the conditional logic similar to 3.1. Future work will include a practical simulation of both suicide and driver fatigue attempt action plans in order to assess the $A Q_{c a b i n}$.

\section{Conclusions}

Poor vehicle cabin air quality has adverse health effects and increases the probability of vehicle collisions. If a continuous gas system is integrated within the vehicle and engine management system of a vehicle several actions can be taken to rectify and improve air quality. For a suicide attempt the exhaust source, the engine, would be ultimately shutdown. For poor cabin air quality at moderate hazardous gas concentrations, warning such as audible and visual could be set. The integration of a gas system for fatigue and suicide prevention must reliably determine both absolute and change in gas concentrations to provide a reliable system to decrease the probability of "false alarms" occuring. 


\section{References}

[1] World Health Organization, Air Pollution WHO Fact Sheet No. 187, September, 2000.

[2] K. Galatsis, W. Wlodarski, Y.X.Li, K.Kalantar-zadeh Vehicle Cabin Air Quality Monitor Using Gas Sensors for Improved Safety, Proceedings of the 2000 Conference on Optoelectronic and Microelectronic Materials and Devices, Melbourne, Australia, December, 2000.

[3] K. Galatsis, W. Wlodarski, B. Wells, S. McDonald, Vehicle Cabin Air Quality Monitor for Fatigue and Suicide Prevention, Proceedings of the Society of Automotive Engineers Exposition Detroit, USA, March, 2000

[4] N.Keates, How safe is airplane air?, The Wall Street Journal, June $9^{\text {th }}, 2000$.

[5] House of Representatives Standing Committee on Communications, Transport and the Arts, Beyond the Midnight Oil: Managing Fatigue in Transport, The Parliament of the Commonwealth of Australia, 2000.

[6] Champion Labs, Kleener Cabin Air Filters, WWW Document], URL http://g04-3-8-000216.bercady.att.net $/ \mathrm{kleener} . \mathrm{html}, 2000$.

[7] V.H. Routley and J. Ozanne-Smith, The impact of catalytic converters on motor vehicles exhaust gas suicides, Medical Journal of Australia, 168, 65-67, 1998.

[8] US National Center for Health Statistics. Compressed Mortality Data, 1992-1996. Searchable on-line at http://webapp.cdc.gov/sasweb/ncipc/mortrate.html and http://wonder.cdc.gov/mortJ.shtml.

[9] N. Cobb, R.A. Etzel, Unintentional carbon monoxiderelated deaths in the united states, 1979 through 1988, JAMA 266(5), 659-663, 1991.

[10] World Health Organization, "WHO guidelines for air quality, 1999", Geneva, 1999.
[11] National Occupational Health and Safety Commission Worksafe Australia, Exposure standards, 2000

12] C. Morgen, J.Schramm, P.Kofoed, J.Steensberg, P.Theilade, Automobile exhaust as a means of suicide: an experimental study with a proposed model, Journal of Forensic Sciences, 1998, 43, 4, 827-836

[13] M.A.Skopek and R.Perkins, Deliberate exposure to motor vehicle exhaust gas: the psychosocial profile of attempted suicide, Australian and New Zealand Journal of Pshychiatry, 32, 830-838, 1998.

[14] M. Shelef, Unanticipated benefits of automotive emission control: reduction in fatalities by motor vehicle exhaust gas, The science of the total environment, 146/147, 93-101, 1994.

[15] H. Fromme, A. Oddoy, T. Lahrz, M. Piloty, U. Gruhlke, Exposure of the population to volatile organic compounds inside an automobile and a subway train. Zentralbl. Hyg. Unweltmed., 200, 505-520.

[16] J. Anderson, Transport ministers attach driver fatigue. Media Release - Australian Commonwealth Department of Transport and Regional Services, December, 1998

[17] E.L. Anderson, R.E. Albert, Risk assessment and indoor air quality, CRC Press, Florida. 1999.

[18] M. Maroni, B. Seifert, T. Lindvall, Indoor Air Quality, Monographs-Vol.3, Elsevier, Amsterdam, 1995.

[19] N. Haworth, P. Vulcan, L. Bowland, and N. Pronk, Estimation of risk factors for fatal single vehicle crashes, Monash University Accident Research Centre, September, 1997. [20] Occupational Safety and Health Administration, USA, OSHA regulations (standards - 29 CFR) permit-required confined spaces - 1910.146. [WWW Document], URL ttp://www.osha-slc.gov/OshStd/data/19100146.html, 1998.

[21] Australian Commonwealth Department of Transport and Regional Services, Intelligent Transport Systems, Australian Commonwealth Department of Transport and Regional Services, 2000. 